\title{
Towards Programs Sustainability: An Exploration of Socio-Economic Determinants for Effective Community Participation in Development Programs in Tanzania
}

\author{
Daniel Wandera Clief Naku ${ }^{1,}$, Jacob Kihila ${ }^{2}$, Eleuther Alphonse Mwageni \\ ${ }^{1}$ Geography Department, St John's University of Tanzania, Dodoma, Tanzania \\ ${ }^{2}$ Institute of Human Settlements Studies, Ardhi University, Dar es Salaam, Tanzania \\ Email address: \\ dnakuclief@gmail.com (D. W. C. Naku), kihilaj@gmail.com (J. Kihila), mwageni@gmail.com (E. A. Mwageni) \\ ${ }^{*}$ Corresponding author
}

\section{To cite this article:}

Daniel Wandera Clief Naku, Jacob Kihila, Eleuther Alphonse Mwageni. Towards Programs Sustainability: An Exploration of Socio-Economic Determinants for Effective Community Participation in Development Programs in Tanzania. International Journal of Sustainable Development Research. Vol. 7, No. 3, 2021, pp. 61-70. doi: 10.11648/j.ijsdr.20210703.13

Received: September 8, 2021; Accepted: September 24, 2021; Published: September 30, 2021

\begin{abstract}
The Late President of the United Republic of Tanzania Mwalimu Julius. K. Nyerere in his book titled freedom and development published in 1973 once stressed that 'if real development is to take place, the people have to be involved'. Similarly, several scholars strongly advocate for the involvement of people in development undertakings that have impact on their day to day lives. On account of such public outcry and views from various scholars with regard to the essence of peoples' involvement in development initiatives within their communities, this study set out to empirically examine the determinants of effective community participation in development programs. Specifically, the study focused on exploring socio-economic determinants for effective community participation in development programs. The study employed a cross - sectional research design and a case study research strategy. Sampling procedures included purposive sampling for key informants and random sampling for programme beneficiaries. By using a 95\% confidence level and Yamane 1967 formula for sample size determination, a sample of 316 program beneficiaries from three study areas of Arusha, Morogoro and Iringa within Tanzania were involved in the study. The findings of the study show that, despite of the existence of several socio-economic determinants for effective community participation in development programs, two determinants i.e., Resource availability and Literacy level of the participants were found to be the major socio - economic determinants for effective participation of community members in development programs. On account of these findings, the study recommends the need to ensure that issues relating to resource availability in any development program and literacy level of the participants need to always be looked into and addressed so that people can effectively participate with the intention of contributing to the sustainability of the
\end{abstract} Keywom.

\section{Introduction}

Community participation is fundamental to achieving sustainable community development in any community [1]. In addition [2] further stresses that the participation of the community in development programs that seek to bring about sustainable development in such a community is very essential. Effective community participation in development projects and programs need to be fully embraced if sustainable development is to be attained in communities [3]. The author further emphasizes that, in order to achieve effective community participation in development programs, there is a need to pay close attention to key factors that serve as determinants and thus ensure that such factors are supportive to the process of community participation in development projects and programs [3].

In support of this view, among other scholars point out that some of these key factors or determinants to effective community participation could be categorized as socio-economic determinants [4]. By definition, Socio-economic determinants are society related economic factors that tend to relate to and influence one another [5]. 
For instance, one's employment level is most likely to influence his or her income.

In the context of this study, some of the socio-economic determinants to effective community participation may include factors such as resource availability, literacy level and economic Structure (ethnicity, income, Class) [4]. The influence of these factors to effective community participation in development programs does vary. For instance, a study noted that some invisible but serious issues characterize the quality and process of participation of people at the community level [6]. Most critical one includes the limited resources to facilitate program activities.

Similarly, another study on community participation in development projects, found that the aspect of economic structure defined by income and class had great influence on level of people's participation in development programs [7]. For instance, the poor and the disadvantaged have low participation level and they cannot be safeguarded in the exploitive social structure unless it is protected by legislation [7]. On the other hand, an empirical study on community participation in education Development projects in Tanzania and the findings revealed that the level of community participation was very low especially in terms of contributing cash by community members [8]. This situation was attributed to the fact that majority of the community members were economically poor and this heavily impacted on the level of their participation.

Generally, the need for effective community participation as one of the means for enhancing programs sustainability is increasingly becoming a pre-requisite for successful implementation of development programs. Unfortunately, in the context of Tanzania, this study found that there was inadequate empirical research on the socio-economic determinants for enhancing effective community participation in development programs sustainability and thus a knowledge gap which in the interest of this paper, it is necessary to be addressed.

\section{Literature}

The need for effective community participation as one of the means for enhancing programs sustainability is increasingly becoming a pre-requisite for successful implementation of development programs in Tanzania and worldwide. It is stressed that development programs at the community level are normally designed and implemented with the intentions of achieving the desired objective of enhancing community development and that they remain sustainable [9]. In addition, it is further stressed that when a program is not sustainable; its impacts decrease leading to unmet expectations and thus affecting development efforts of the community as a whole [10]. In order to avoid this situation, it is suggested that active participation which is open and allows community members to actively take part in all stages of the program is essential for the sustainability of a program [11].

This leads to capacity building, which enables the community to be more effective and efficient in the process of identifying, monitoring and evaluating the program and thus contributing to its sustainability [11]. In addition, community participation allows beneficiaries to influence the direction and execution of development programs rather than merely receive a share of the program [12]. Similarly, according to the 2013 Human Development Report, in order to walk in the human development pathway, people should engage fully in activities that reform the lives and they should be able to participate in policy making process and results [13].

In general, this paper stresses that there is enormous empirical evidence that strongly point to the fact that community participation in developing countries is a key component in the sustainability of development programs. For instance, the National Irrigation Authority (NIA) in the Philippines ran irrigation programs which were developed with community participation component. The impact of participation of local groups was significant as yields were between $10-22 \%$ greater, water use was more efficient, farmers contributed seven times as much to costs, and new structures were likely to be maintained [11].

Similarly, in Nepal, the Small Farmer Development Programme (SFDP) also showed that the benefits of working with community groups were equally more. Compared with non-participatory programs, the SFDP was successful at improving agricultural yields; diversifying production; increasing recovery rates for loans and improvements in welfare of the poor [11].

In addition, to test whether participation led to the sustainability of programs and projects an investigation of the state sponsored community infrastructure development projects implemented as part of the Reconstruction and Development Programme was carried out [14]. The research determined sustainability at project, personal and community levels [15]. At a project level, it was found that where participation took place, human capital was enhanced through training and experience. This led to the acquisition of soft and hard skills which were later used by beneficiaries to complete and maintain projects in the longer term [15].

Conversely, less participatory projects were less likely to be completed and those that completed the projects failed to maintain the projects or use them as a springboard for furthering their gains [15]. Hence, the more active beneficiaries were in the projects, the more sustainable projects seemed to be [16]. These findings are corroborated by the findings that in most instances, the participation of communities in projects led to greater overall effectiveness and a greater chance of sustainability of projects in the longer term [17].

On the basis of the above views, community participation can be seen as an essential component in ensuring that development programs are sustainable to meet the needs of the community while at the same time facilitating community development in that particular community. However, the pre-requisite determinants for effective community participation to occur in development initiative such as programs and project may be contextual and specific to 
particular locations.

As pointed out earlier, Socio-economics also referred to as socioeconomics, is concerned with the relationship between social and economic factors within a society [18]. As such, socio- economic related determinants include those factors that influence how a particular group or socioeconomic class behave within society, including their actions. Different socioeconomic classes may have different priorities. Similarly, the extent of involvement in any development program by people can be influenced by these factors. Some of these determinants as documented in literature include resource availability, literacy level as well as economic Structure based on income levels [19].

For instance, in the case of literacy level, the study revealed that people in Chad value education greatly and therefore local contributions to the cost of education have been a long-standing tradition in the country [20]. This explains the efforts of local communities to participate in financing operations in schools even when the education system worsened due to civil war of 1979-1982. The government had been aware of the reality that the communities play an important role in the school system and, requested the World Bank to prepare a project to involve local people and respond to their real needs [20].

In order to ensure various stakeholders' participation, the project preparation was carried out involving various groups of people. First the government organized four region conferences, engaging members of local school associations, representatives of NGO'S, Women's groups as well as ministry officials, school's inspectors, school directors and teachers. At the meetings participants discussed the local primary education problems and strategies to overcome them. The discussion helped tell that Chadians at the local level are seriously committed to and carefully involved in educating their children.

In terms of economic structure which is defined by class and income it was found that participation of local communities in development projects planning in the study conducted in Bangladesh was low because participation was limited to the rich and socially influential persons, without whom the elected representatives cannot think of their political successes [21]. For resource availability as a socio-economic determinant, a study noted that limited resources to facilitate program activities was one of the most critical factors that influenced the level of participation in development programs by community members [6].

Generally, from the above literature, it can be summed up that the influence of socio-economic determinants cannot be underestimated in influencing the participation of community members in development. However, in the context of Tanzania, empirical analysis of such determinants was found inadequate.

\subsection{Study Conceptual Framework}

On account of the reviewed literature, socio-economic determinants such as resource availability, literacy level, and economic structure that includes the level of one's income and the aspect of class were identified as possible influencing factors to participation of community members in development programs. Figure 1 below conceptually sums up these factors and how they are linked to effective community participation and the sustainability of development programs.

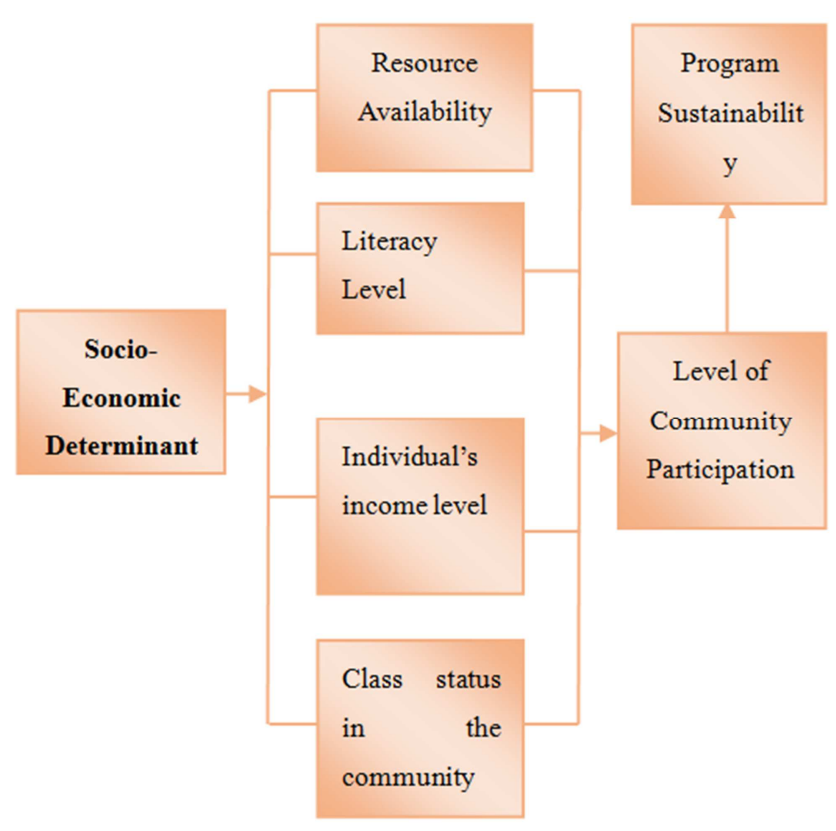

Figure 1. Socio-economic Determinants

\subsection{Conceptual Framework Logic and Narrative}

The logic and narrative behind the conceptual framework presented in figure 1 is that socio-economic determinants have influence on development program sustainability through the manner and extent of community participation in such development program. However, the manner and extent of community participation is dependent of various socio-economic determinants which may include resource availability, literacy level, individual's income level and class status in the community among others.

\section{Methodology}

The study employed a cross - sectional research design and a case study research strategy. The cross-sectional research design was used because it is best suited for studies that aim at finding out the prevalence of a phenomenon, situation, problem, attitude or issue, by taking a cross-section of the population. In addition, it is stressed that cross sectional designs are useful in obtaining an overall 'picture' as it stands at the time of the study and designed to study some phenomenon by taking a cross-section of it at one time [22]. As such, this design was chosen in line with the above stated views whereby the researcher was interested in examining socio-economic determinants of effective community participation in development programs.

On the other hand, the case study research strategy was used because it is open to use of other approaches of analysis including both qualitative and quantitative approaches that the study intended to use. As observed, case study research 
can accommodate both qualitative and quantitative approaches, thus allowing the researcher to get a rich mix of data for the study [23].

Sampling procedures included purposive sampling for key informants and random sampling for programme beneficiaries. Using a 95\% confidence level and Yamane 1967 formula for sample size determination, a sample of 316 program beneficiaries from three study areas of Arusha, Morogoro and Iringa within Tanzania were involved in the study. This sample size was drawn from four examined program categories that included pure locally funded program, pure government funded program, and donor funded program as well as the joint funded program.

Findings of the study were analysed based on two analysis approaches that included the within case analysis and comparative case analysis. The within case analysis which is an analytical approach in which each single case in the study is examined independently and in detail while the comparative case analysis is an analytical approach used to compare findings from different single analysed cases. In the case of this study, four development programs were first analysed independently and later the findings from each case were compared.

\section{Results and Discussion}

\subsection{Results and Discussion Based on the Within Analysis}

\subsubsection{Within Analysis for Locally Fully Funded Development Programs}

Based on the within case analysis for the examined pure locally funded development program, results of the study revealed some of the factors in the context of the examined program were influential in determining the participation of people in the program.

According to study respondents of the examined program, three Socio-economic factors were pointed out as key determinants in influencing the level of effective community participation in pure locally funded development programs. These determinants included literacy level where by $64.6 \%$ of the respondents stressed this factor. The interviewed study respondents pointed out that knowing how to read and write was very important for them because a large component of this program was on knowledge transfer through trainings. Study respondents believed that when someone could read and write, he or she had the ability to follow what the program was about and could constructively contribute to the program. In addition, they also pointed out that this boasted someone's confidence to freely express him or herself in public. In quotes, one of the interviewed respondents stated...,

'If you cannot write and read, you feel disappointed when you meet other people because this program involved a lot of being trained by officers from Kinara. So, if you can't write and read, you cannot attend such a program,

In the same spirit, during the Focus Group Discussion, a similar perception was echoed by participants who mainly emphasised that, since the program is designed to assist youths stay away from activities that would lead them to engage in sexual reproductive activities through knowledge transfer and awareness, a lot was on provision of training and therefore there was a need for people to at least know how to read and write.

However, according to the Program Coordinator, this was not a criterion for one to be part of the program but to the youths this was an issue which made the program to come up with other strategies of encouraging any interested youth to join the program. For instance, the program implementers introduced a community library where youths would come for personal learning on how to read and write under the guidance of an officer from the implementing organization. In quotes, the Program Coordinator lamented that...,

'Most of the youths in this program are school dropouts at primary and secondary education level. Some of them cannot read or even write. As such, we have a component of providing some training on reading and write to help them find it comfortable to participate in the program'

The findings on the literacy level as a socio-economic determinant for effective community participation in development programs was found to be in line with findings from other scholars. For instance, people in Chad value education greatly because of the importance it offered them in terms of enabling them to effectively participate in development activities within their communities [19, 20]. Similarly, in the context of this study, literacy level was revealed as one of the key determinants for enabling people effectively participate in pure locally funded development programs.

Other socio-economic determinants that were revealed by study respondents included resource availability in the program and economic structure mainly based on having some income. The analysis showed that $24.3 \%$ of the respondents considered resource availability in the program as one of the crucial factors that enabled youths to participate in the examined pure locally funded development programs. According to this group of respondents, if the program does not have resources to support its activities, there is a lot of comprise on how the activities are carried out. Both program implementers and targeted program beneficiaries struggle to realize the implementation of program activities in the absence of resources within the program. In quotes, a study respondent pointed out,

'Participating in a program on voluntary basis is very difficult and, in our case, we don't get any funding from the program. But if such support had been available, I am very sure so many people would have joined the program. Some of our friends have left the program because they find it difficult to participate due to lack of resource support from the program'

This finding concurs with the findings in a study that noted that some invisible but serious issues that characterize the quality and process of participation of people at the community level from the socio-economic point of view was limited resources to facilitate program activities [6]. This therefore implies that; availability of resources is equally an important factor in determining the participation level of 
people in pure locally funded programs.

With regards to the economic structure factor, $11.1 \%$ of the study respondents also considered this as another socio-economic determinant for effective community participation in pure locally funded development programs. This factor was largely attached to having some income that enabled one to easily participate in the activities where some funding was needed as opposed to the aspect of social class. The findings to some extent agree with the views presented in other studies. For example, in their studies on community participation in development projects, it was found that the aspect of economic structure defined by income and class had great influence on level of people's participation in development programs [7, 21]. Two things to note with this finding are that, in the context of this study, economic structure based on income level was not a major factor although it manifested. Secondly, economic structure based on class was completely not an issue and was therefore not seen as a determining factor in the examined pure locally funded program.

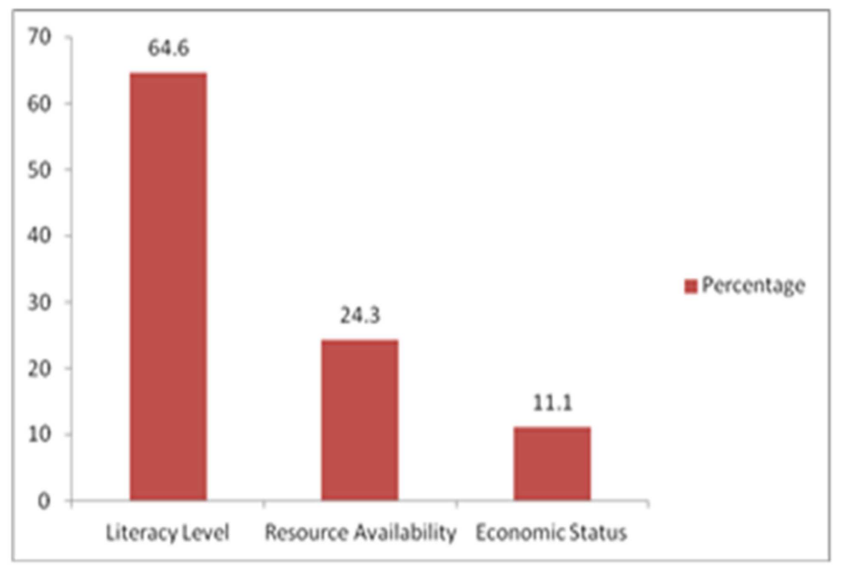

Source: Field Survey, 2020

Figure 2. Socio-economic Determinants in Locally Fully Funded Development Programs.

Generally, as much as the aspects of resource availability in the program and economic structure were raised during the face-to-face interviews with individuals, these issues were not seen as determining factors in the Focus Group Discussions. Members in the Focus Group Discussions pointed out that from the start, program implementers had explained the operations of the program to them and for that matter having no or limited resources by the program implementers as well as not being economically well off would not be issues to deter an individual from participating since participants already knew the nature of the program. As quoted from one of the members in the FGD,

'The greatest shame to us as youths in this program was in not knowing how to read and write; Otherwise, whether the program was to support us financially or you had money or not were not serious determining factors for our participating in the program'

These results demonstrate that despite of the fact that some authors have pointed to the fact that the extent of community participation in development programs may be affected by socio-economic factors such as resource availability, literacy level and economic status relating to income level and social class, in the context of this study and specifically for the examined pure locally funded development program, the issue of literacy level was found to be the most influential factor.

From the researcher's point view, these findings may be attributed to the fact that the main key component of the program was on imparting sexual reproductive education to youths and as a result, training and sensitization aspects were major program activities. However, it was important to note that, although resource availability and economic status as were not found to be key in this particular program, they could be key in other pure locally funded programs with different program focus from that of providing training and sensitization as it was the case with the examined program in this study. Figure 2 presents a summary of the findings on this aspect.

\subsubsection{Within Analysis for Government Fully Funded Development Programs}

In the examined pure government funded development program, findings from the within case analysis on the Socio-economic determinants for effective community participation revealed that two key factors were pointed by study respondents as being influential in determining people's participation in development programs of this nature.

According to study respondents in the examined program, $78.6 \%$ of the respondents pointed out that resource availability in the program was the most crucial factor for people's participation in the program. The interviewed respondents indicated that without resources, there was no way one could engage in undertaking a government program. In quotes, one of the interviewed revealed that.

'You need resources for you to implement a government program because these are not small programs, usually they are concerned with provision of social services and there is no way you will escape not needing to have resources. If it is a community-initiated program, then people may find ways of handling it without worrying about resources but you cannot do that for most government programs'

This view was equally shared by both the Secondary Education Officer and the Office in Charge of Statistics, Monitoring and Evaluation of programs in schools as key informants. The two key informants ultimately in quotes pointed out that...,

'For government programs, resource availability is a crucial factor. All things including the participation of people will in one way or another require resources because once people know that it is a government program, they will want to be facilitated for everything such as attending meetings etc. So, it is very important that the needed resources are actually available otherwise, nothing will materialize'

These findings show that unlike in the examined pure 
locally funded program, the issue of resource availability was highly stressed in the examined pure government funded programs. These results tend to concur with the views of other scholars. For instance, as noted that limited resources to facilitate program activities could largely impact people's participation in that particular development program [6].

The other Socio-economic determinant that was pointed out as being of relevance to people's participation in pure government funded programs was the literacy level. This factor was attested to by $21.4 \%$ of the study respondents who pointed out that most government programs come with a lot of documentation explaining so many things. As such, one has to be able to read and understand them to be able to participate. In quotes, the interviewed stated that...,

'If you can't read and write, dealing with government programs of this nature might end you in trouble. You need to understand what the program is about, why you sign some documents etc. The local person may need to know how to read but if you are in a position of leadership like mine and you take things for granted, you can pay a penalty when things go wrong'

This finding largely concurs with findings of other scholars where education was found to be important in addressing literacy issues among people so that they could easily participate in development activities within their communities [19].

Overall, from the Socio-economic point of view, these two factors were highly stressed as the determining factors for people's participation in pure government funded development programs of this nature. These findings conform with the views of several authors who pointed out that socio-economic factors of this nature if not addressed may greatly affect the extent of people's involvement in any development initiative $[6,8,19]$.

In this regard, the findings on socio-economic determinants for effective community participation in pure government funded development programs revealed that indeed people see social-economic determinants such as resource availability and literacy level as being influential and a threat to their effective participation in such programs. This implies that, influencing community participation in pure donor funded development programs may not necessarily be from a single stand-alone factor, rather, combination of various socio-economic factors may come together to influence the extent to which people get involved in such development programs. Important to note is that, even in their combination, each factor will have its own level of influence. Figure 3 presents these findings.

\subsubsection{Within Analysis for Donor Fully Funded Development Programs}

Just like the previously examined development programs, effective community participation in pure donor funded development programs can equally be influenced by a number of social economic factors.

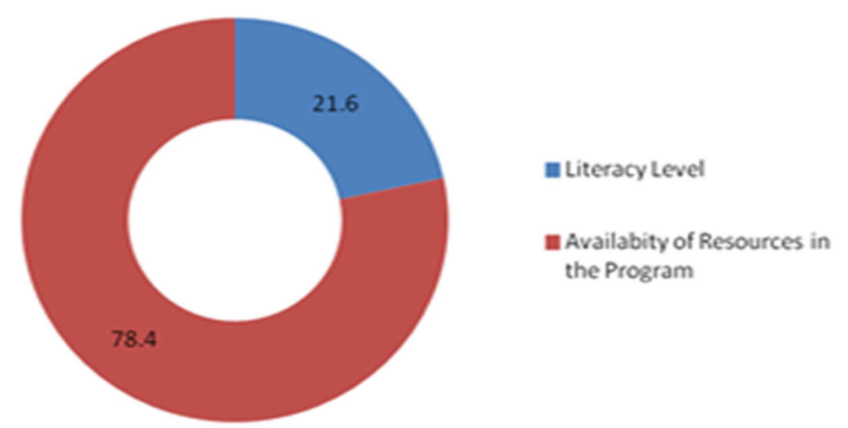

Source: Field Survey, 2020

Figure 3. Socio-economic Determinants in Government Fully Funded Development Programs.

The within case analysis on the Socio-economic determinants for effective community participation in the examined pure donor funded development program revealed that $69.2 \%$ of the study respondents pointed to the fact that resource availability in the program was the most critical factor in influencing their participation in the program. This finding concurs with the views in a study that revealed that limited resources to facilitate program activities could greatly impact the participation of people in the program [6].

According to the interviewed respondents, participating in a program of this nature would have been very difficult if there were no resources to support the participants. For instance, participants were required to purchase tree seedlings, attend trainings etc. All these activities according to participants needed support from the program implementers so as to enable the interested persons to participate in the program. As such, incentives in the form of seed provision and facilitating participants to attend trainings were made available to all persons who were interested in participating in the program. In quotes, one of the interviewed respondents stated that.

'There was no way I would have joined this program if I was not sure that I would be offered support by the program. Cultivating trees require you to have some resources to buy tree seedlings, buy pesticides among others. On my own, this would have been a problem'

A similar perception was shared by members from the Focus Group Discussions. According to them, cultivating trees on two acres which wasn't a food or cash crop that you would harvest in short run was considered as an expensive venture. Hence, the availability of resources in the form of incentives was very important to enable people to participate in the program.

In addition, the Forest Field Facilitator as a key informant further stressed that given the nature of the program, without support to participation, such program would have been difficult to implement. Hence, findings from the Focus Group Discussions and key informant were in agreement with the views of the interviewed study respondents. 


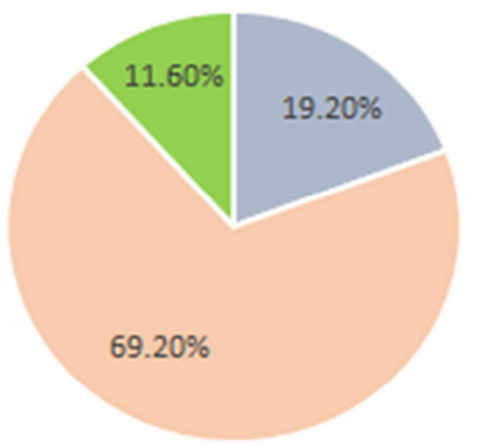

" Literacy Level " Resource Availability " Any Other

Source: Field Survey, 2020

Figure 4. Socio-economic Determinants in Pure Donor Funded Development Programs.

Besides the availability of resources in the program, $19.2 \%$ of the respondents also revealed that someone's literacy level was equally an important socio-economic determinant in the participation of an individual in the program while $11.6 \%$ revealed that there were also other factors such prior knowledge in tree cultivation, future expectations among community members also served as determinants for one's participation in the program [18].

According to the Program Coordinator as a key informant, although literacy was not a key factor for one to join the program, the nature of the program had lots of training which involved taking field notes. As such, it was at times challenging for some participants but through their own support mechanisms, even those people who had no formal education but had prior knowledge or interest in the program were allowed to join the program. Figure 4 presents the findings of this analysis.

\subsubsection{Within Analysis for Joint Funded Development Programs}

The analysis on socio-economic determinants for effective community participation in joint funded development programs as noted from the examined program revealed that three factors were cited by study respondents as key factors that were influential in people's participation in the program. These factors included availability of resources in the program, presence of the government in the program which was captured as any other factor and literacy level of the participants.

In fact, according to the study respondents, out of the three factors, availability of resources and the presence of the government captured as any other factor were the most crucial factors that were said to have influenced many people to join the program. From the respondents, $45.7 \%$ attested that their involvement in the program was largely influenced by the availability of resources in the program, a factor that is equally stressed $[18,6]$. While $43.7 \%$ indicated that the presence of the government in the program was a crucial factor for their involvement in the program.

Concerning the factor of availability of resources in the program, study respondents pointed out that it was necessary for the program to support them especially when starting since most of them did not have the capacity to access things like quality seeds for cultivation. In this regard, the program in its first phase loaned farmers seeds at affordable price and farmers were required to repay slowly in instalments without any pressure. As revealed by one of the interviewed respondents...,

'...the support that the program rendered to people during the starting period of the implementation of the program helped most of us to find it easy to join the program. For instance, we were assisted with affordable seeds on loans and incentives in form of cash for improved performance,

This view was also largely shared by members in the Focus Group Discussions who pointed out that, the joining of many people to the program was mainly influenced by the fact that the program began by assuring those who joined the program support. As such, people were trained, provided with quality seeds on affordable loans and after taking off, the program provided incentives in the form of cash to assist those who were performing well to further improve on their tree farms. In quotes, Focus Group Discussion Members stated that...,

'Most of us are peasant farmers and yet the program aimed at helping people grow quality trees that they would sell and earn income in future. Buying quality seeds was going to be an obstacle to many of us joining the program but when we were assured of support by PFP, then most of us joined'

This perception was further confirmed by both the Program Director and the Forest Information System Field Officer as key informants. According to them, the initial plans were to support program beneficiaries by providing them with the needed training and skills on how to prepare a tree farm and planting of trees. Unfortunately, on holding community meetings with residents in the program areas, the issue of how to access quality seeds was brought up in which people expressed concern on the challenge of getting quality seed as a result of high costs. As a major threat to the program, this was addressed by the program which made people gained interest to participation in the program.

Besides the availability of resources as earlier pointed out, study respondents also revealed that the presence of the government in the program was another convincing factor that encouraged them to join the program. This view was attested to by $43.7 \%$ of the study respondents who in their view revealed that by seeing the government involved in the program, this gave them more confidence in the program. In quotes, one of the interviewed respondents lamented that...,

In the past, we have been conned by people who come here that they have brought us programs to help us out of poverty and yet they have their own intentions. So, when we saw that this program has the hand of the government then that was enough proof that it is a genuine program for use to join'

These two factors were highly stressed as the most 
influencing factors although $10.6 \%$ of some of the interviewed program participants also revealed that the factor of literacy was equally an important factor that assisted them in their participation in the program. According to the interviewed, the program had a training component which meant that one had to take field notes as well as reading to understand guidelines that were given to them. Hence, this group of the interviewed felt that, to some extent, this factor was equally influential to them.

On the contrary, according to the Program Director as a key informant, besides the issue of resource availability that was brought up during the early days of introducing the program to community members, issues of literacy and the presence of the government were not taken as serious determinants for people's participation in the program because they had already taken care of these during the program design. In quotes, the Program Director stated that...,

On our part we saw the issue of supporting participants with some resource elements as a crucial factor but I think on the part of the participants as they informed you, having the government in the program was important for them. For sure, I am also getting to know this right now because I did not expect it since the program was from the start designed to be implemented by two governments. With, literacy, this could be probably true for some very few people because we are more field based and therefore very practical. You don't need to know how to read and write to join the program. We will train you practically in the field and that is why we started by training field officers and these had prior knowledge on tree farming'

Basically, from the views of the interviewed participants and those of the key informants as well as members from the Focus Group Discussions, this study found that, socio-economic determinants that appeared to have influenced people's participation in the examined joint funded development program were mainly resource availability, government presence and to some extent literacy level of some participants. These findings concur with findings from other studies $[6,19,18]$. Figure 5 presents the findings of this analysis.

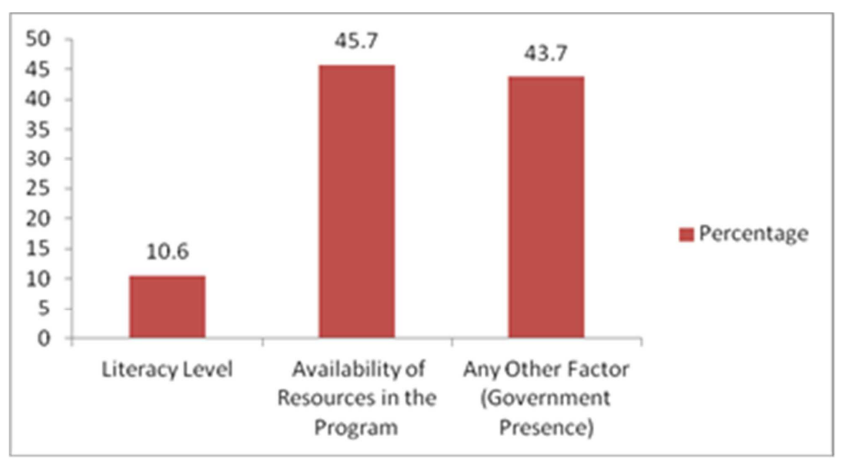

Source: Field Survey, 2020

Figure 5. Socio-economic Determinants in Joint Funded Development Programs.

\subsubsection{Results Summary Based on the Within Analysis for the Examined Four Programs}

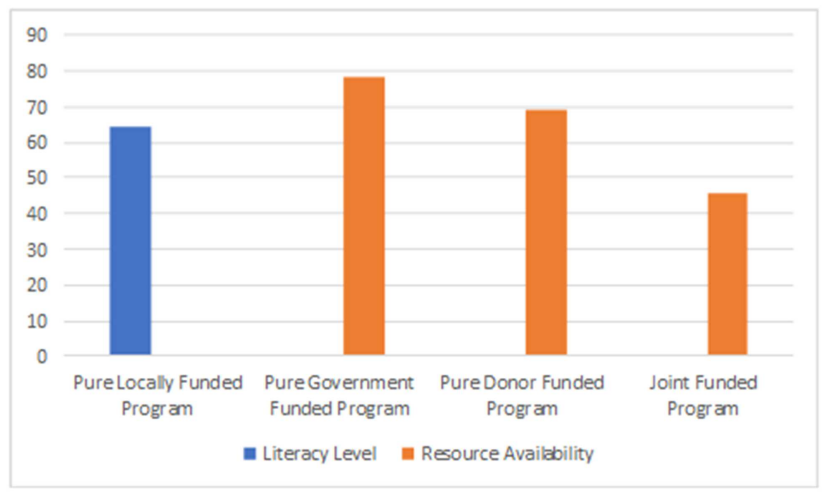

Source: Field Survey, 2020

Figure 6. Results Summary Based on the Within Case Analysis for Socio economic Determinants.

Based on the within case analysis for each examined development program, summary results showed that in the pure locally funded development program, the factor of literacy level among program beneficiaries was the most determining socio-economic determinant for influencing people's participation in the program by $64.6 \%$ followed by resource availability with $24.3 \%$. In the remaining three examined development programs i.e., Pure government funded program, Pure donor funded program and the joint funded development program, the factor of resource availability was found to be more influential in three programs by $78.4 \%, 69.2 \%$ and $45.7 \%$ respectively. Figure 6 below presents the summary of these results.

\subsection{Results and Discussion Based on the Comparative Case Analysis}

Comparative Case Analysis was undertaken to enable the researcher to drawn general conclusions after observing the results from the four examined development programs. Hence, based on the comparative case analysis, this study found that factors such as literacy level, resource availability and economic status were cited by study respondents in the four examined programs as having been influential in their participation in the programs. However, the study also found that other factors such as government presence and prior knowledge in activities of some of the programs also played a role in influencing people's participation in those programs.

Importantly, the study noted that, although some factors such as literacy level and availability of resources were cited to be influencing factors in all the four examined programs, their intensity of influence as perceived from the interviewed respondents varied from one program to another. For instance, in the examined pure locally funded development program, $64.6 \%$ of the respondents indicated that the factor of literacy level was very influential while in the pure government program it was $21.6 \%$, in the pure donor funded program it was $19.2 \%$ and in the joint funded program it was $10.6 \%$.

In the case of resources availability in the program as a 
cross cutting factor, $24.3 \%$ in the pure locally funded program perceived it that way, $78.4 \%$ in the pure government funded program, $69.2 \%$ in the pure donor funded program while $45.7 \%$ in the joint funded program. With the exception of the findings in the pure locally funded development program where the factor of resource availability only came second after the factor of literacy level, in all the remaining three programs, the factor of resource availability was cited as the most influencing factor.

On the basis of these findings, this study affirmed that from the various socio-economic factors that had been put forward by various authors, the factor of resource availability whose average influence as shown in Table 1 was $54.4 \%$ stood out as the most influencing socio-economic determinant for people's effective participation in development programs.

This implied that regardless of the nature of the program, addressing the factor of resource availability in the program as a socio-economic determinant is of paramount importance if effective community participation is to take place as revealed in Table 1.

Table 1. Major Socio-economic Determinants

\begin{tabular}{lllllll}
\hline Socio- Economic & \multicolumn{2}{l}{ Percentage Scores (\%) } & & \multirow{2}{*}{ (\%) } & \multirow{2}{*}{ Rank } \\
\cline { 2 - 6 } Determinants & Locally Funded & Gov't Funded & Donor Funded & Joint Funded & 54.4 & $1^{\text {st }}$ \\
\hline Resources & 24.3 & 78.4 & 69.2 & 45.7 & 29.0 & $2^{\text {nd }}$ \\
Literacy & 64.6 & 21.6 & 19.2 & 10.6 & 29 & \\
\hline
\end{tabular}

Source: Field Survey, 2020

Nevertheless, the study noted that, despite of the fact that the factor of resource availability was cited as the most influential factor, the other cited factors such as literacy level, economic status, presence of the government and prior knowledge in the program activities cannot be under estimated if meaningful participation in development initiatives as advocated for by authors was to prevail [1, 2, 19, 24].

\section{Conclusion, Study Implications, Contributions and Future Research Directions}

\subsection{Conclusion}

In this study, we have sought to respond to a fundamental research question from an empirical point of view on what could be the socio-economic determinants for promoting effective community participation in development programs so as to enhance program sustainability in the context of Tanzania. In this part of the paper, we conclude by briefly foregrounding some of the study's implications for practice, and some of the directions for future research that stem from the study.

\subsection{Study Implications}

Based on the study findings, the study revealed that from the socio-economic perspective, the following are key study implications for practice;

Ensuring that there is resource availability in any program should never be undermined regardless of the nature of the program. Resource availability from the socio-economic determinants point of view plays a very crucial role and can therefore greatly contribute to effective community participation in development programs.

Literacy level of participants in any development program should also be given due consideration depending on the nature of the program.

Paying attention to the factor of resource availability and literacy level should never imply ignoring other minor socio-economic determinants such as income level and class mong others if meaningful participation where all concerned individuals need to be brought on board is to be achieved.

\subsection{Study Contributions}

Accordingly, the first major practical contribution of this research is that it provides much needed empirical knowledge and information on the key socio-economic determinants for effective community participation in development programs in Tanzania. Precisely those determinants include resource availability and the issue of literacy level among program participants.

Secondly, another major contribution of the study is that it has revealed that depending on the program funding mechanism i.e., Pure locally funded, Pure government funded, Pure donor funded or Joint funded program, social economic determinants will vary from one program type to another. To this effect, the study summed up by indicating that it can never be assumed that one socio economic factor can have the same impact across different program categories as observed from the findings of the study.

\subsection{Future Research Directions}

Our study, being of an exploratory and interpretive nature, raises a number of future research opportunities, both in terms of theory development and concept validation.

First, this study much dwelled in examining what could be the socio-economic determinants for effective community participation in development programs from an empirical point of view. In this case, the question of how practical could those socio-economic determinants be operationalized was never addressed and therefore this could be a new insight area for further investigation.

Second, this study only provides an analysis of socio-economic determinants but besides these socio-economically defined determinants, there could also be other determinants that may be influential in determining the 
participation of people in development programs so as to enhance program sustainability. Exploring such determinants could also be a new insight for further investigation.

Lastly, examined programs in this study are mainly categorized on the basis of the funding mechanism i.e., pure locally funded, pure government funded, joint funded and donor funded. However, it is very possible to adopt a different categorization and examine community participation in such categories. For instance, programs could be examined on the basis of their scale of coverage such as small-scale program, medium-scale program or large-scale program.

\section{Acknowledgements}

We are grateful to all those who participated in this study. In particular, we extend our appreciations to study participants in Iringa, Morogoro and Arusha.

\section{References}

[1] Beck. A \& Crawley. C (2002): Education, ownership and solutions: the role of community involvement in achieving grass roots sustainability, Regional Institute Online Publishing, North South Wales, Australia.

[2] Schutte, D. W. (2000): Community Development and Community Participation: A Conceptual Revisit. Entwicklungsethnologie, 9 (1), 12-26. Retrieved from https://www.academia.edu/28898875/CommunityDevelopmen t_and_Community_Participation_a_Conceptual_Revisit_De_ Wet_Schutte_1.

[3] Odoyo. C (2013): Factors affecting implementation of community projects: Case of Kimira-Oluch smallholder farm improvement project in Homa Bay County, Kenya. Universal Journal of Management, 1 (2), 111-118.

[4] Masanyiwa. Z. S and Kinyashi. G. F (2008): Analysis of Community Participation in Projects Managed by Non-Governmental Organizations, Institute of Development Studies, London, UK.

[5] Berman, $\mathrm{T}$ (2017) Public Participation as a Tool for Integrating Local Knowledge into Spatial Planning, Department of Geography and Human Environment, Tel. Aviv University, Isreal, Springer International Publishing.

[6] Asaduzzaman, M (2008): Governance in Practice: Decentralization and People's Participation in Local Governance. Published PhD Thesis, University of Tampere Press.

[7] Nazneen, D. R. Z. A (2004): Popular Participation in Local Administration: A Case of Gyan Bitarani, Dhak.

[8] Mnaranara. T (2010). The importance of community participation in construction of primary schools. A Case study of Mlali and Mzumbe ward. University of Agder, NorwayUnpublished Thesis.
[9] Bamber. J, Owens. S, Schonfeld. H, Ghate. D and Fulerton. D (2010): Effective Community Development Programs: A Review of International Evidence Base. Published by the Centre for Effective Services, Dublin, Iceland.

[10] Sebastian. I. C, Eduard. G. C, Cristian, E. L and Luliana. L (2018): Community Based Programs Sustainability. A Multidimensional Analysis of Sustainability Factors.

[11] Wasilwa. C (2015): Effects of Community Participation on Sustainability of Community Based Development Projects in Kenya, Unpublished.

[12] Akumu. M and Onono. P (2017): Community Participation and Sustainability of the Kenya Comprehensive School Health Program in Kajiado County, Kenya, Unpublished.

[13] UNDP (2013): Human Development Report. The Rise of the South: Human Progress in a Diverse World, New York.

[14] Monaledi, MHA (2016): The relationship between community participation and the sustainability of CSR projects. The case of Groutegeluk coal mine in Lethalale local municipality, North-west University. Unpublished.

[15] Lyons, M., Smuts, C., \& Stephens, A. (2001). 'Participation, empowerment, and sustainability: (How) do the links work?'. Urban Studies.

[16] Khwaja, A. I. (2001), Can good projects succeed in bad communities? Collective action in the Himalayas" Harvard University, Department of Economics, Cambridge, Mass.

[17] Mansuri, G. and Rao, V. (2004), Community-based and driven development: A critical review. The World Bank Research Observer.

[18] Evan, T (2019): Understanding Social Economics. Retrieved from

https://www.investopedia.com/terms/s/social-economics.asp.

[19] Mwiru. M. S (2015): The Importance of Community Participation in Development Projects at the Local University. Mzumbe University- Unpublished.

[20] Uemura, M. (1999). Community Participation in Education. What do we know? The World Bank. United Republic of Tanzania, Local Government Reform Programme Policy Paper on Local Government Reform. Ministry of Regional Administration and Local Government. Dar es. Salaam, October, 1998.

[21] Sheikh, N. (2010). People's Participation in Development Projects at Grass-root Level: A case of a Lampur and Jagannathpur Union Parishad. North South University, Bangldesh.

[22] Kumar. R (2011): Research Methodology: A Step-by-Step guide for beginners, $3^{\text {rd }}$ Edition, SAGE Publishers, New Delhi, India.

[23] Yin, R (2003): Applications of Case Study Research (2nd ed). Thousand Oaks: Sage Publications, London.

[24] Arnstein. S (1969): The Ladder of Citizen Participation. The Journal of the American Planning Association, 35, (4): 216-224. 